\title{
Quality Standards and Techniques for the Application of Focused Shockwaves and Radial Pressure Waves in Musculoskeletal Disorders
}

\author{
José Eid ${ }^{1}$, Daniel Moya ${ }^{2}$
}

\section{Abstract}

Focused shockwaves and radial pressure waves are safe and effective if used correctly. Nevertheless, poor results and complications have been described due to missdiagnosis and technical errors. The aim of this review is to introduce the basic principles of quality and technical recommendations for each method.

Keywords: Shock waves, Radial pressure waves, Quality standards.

\section{Introduction}

Since its inception in the late 1980s [1], the use of Extracorporeal Shock Wave Therapy (ESWT) in the treatment of musculoskeletal pathology has grown steadily. A great deal of scientific evidence and indications have been added [2]. Its use in combination with other regenerative techniques has been advocated. There is an availability of a wide range of equipment. Many medical and non-medical specialties have incorporated shock waves as a therapeutic tool, not always having in-depth knowledge of the pathology to be treated, not always respecting professional scopes.

There is an educational offer that includes scientific societies, universities, industry, and even beginners, who simply by having access to social media become opinion makers.

This panorama makes it essential to have quality standards including recommendations and guidelines to meet them.

To complicate matters even more "shock wave" term includes two technologies used in the field of musculoskeletal pathology. Focused shockwaves (F-ESWT) and Radial pressure waves (RPW). They present clear different physical parameters $[3,4]$. They have shared indications and contraindications, and others that are specific to each method $[1,5,6]$.

The aim of this review is to introduce the basic principles of quality and technical recommendations for each method.

\section{Physical Principles and Generators}

Two basic types of technical principles are included in ESWT: focused ESWT (FESWT) and RPW, which are often referred to in the literature as radial shockwaves. However, we must point out that shock waves and pressure waves can also be planar or defocused. Some radial pressure wave sources have applicators that can slightly focus the pressure field.

Focused shock wave devices have classically three types of generators: electrohydraulic, electromagnetic, and piezoelectric.

RPW devices have two types of generators: electropneumatic and electromagnetic. These devices do not emit shockwaves because the rise times of the pressure pulses are too long and the pressure outputs are too low $[2,3]$. Nevertheless, RPW may induce acoustic cavitation [2].

The modes of action and the effects of RPW on living tissue may differ from those of focused shockwaves because bioeffects are related to the pressure waveform [2].

The level of risk associated with focused generators is different from that associated with radial sources [7]. For this reason and according to the consensus of most scientific societies $[5,6,8]$, focused devices should be operated only by trained physicians.

Non-physicians, as nurses, physiotherapists or technicians may perform RPW after previous diagnostic and prescription by trained physicians $[5,6]$.

\section{Diagnosis}

Diagnosis should be the initial step in the indication of any treatment. Unfortunately, this obvious concept presents many distortions in practice. Kibler [9] has stated that a great effort has been put into developing new therapeutic techniques but there is no proportional interest in improving our diagnostic ability.

Most of the poor results of shock wave treatment are related to an improper diagnosis [10].

The International Society for Medical Shockwave Treatment has developed a list of approved clinical indications that are based on the strength of the supporting evidence (Table 1) $[2,11,12]$. The indications are divided into standard approved, empirically proven, exceptional or expert indications, and experimental indications $[11,13]$.

Whoever performs the treatment must not only be able to have an accurate diagnosis but also know the characteristics of the pathology to be treated and the possible complications related to it. The existence of pathology associated with the most obvious one should

${ }^{1}$ Médico Assistente do corpo clínico do Hospital Hcor São Paulo, Brazil,

${ }^{2}$ Servicio de Ortopedia y Traumatología, Hospital Británico de Buenos Aires, Argentina.

Address of Correspondence

Dr. José Eid, MD,

Médico Assistente do corpo clínico do Hospital Hcor São Paulo, Brazil.

E-mail: j.eid@uol.com.br
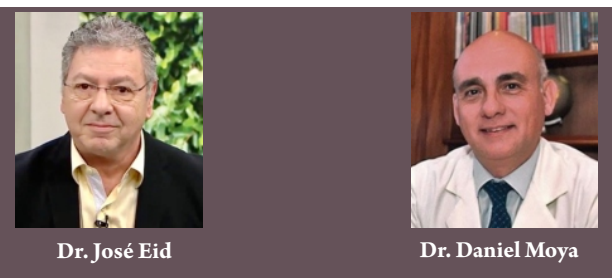

Submitted Date: 15 June 2021, Review Date: 15 July 2021, Accepted Date: 16 August 2021 \& Published: 31 December 2021

(C) 2021 by Journal of Regenerative Science | Available on www.jrsonweb.com | DOI:10.13107/jrs.2021.v01.i01.007

This is an open access journal, and articles are distributed under the terms of the Creative Commons Attribution-NonCommercial-ShareAlike 4.0 License (https://creativecommons.org/licenses/by-nc-sa/4.0/), which allows others to remix, tweak, and build upon the work non-commercially, as long as appropriate credit is given and the new creations are licensed under the identical terms. 


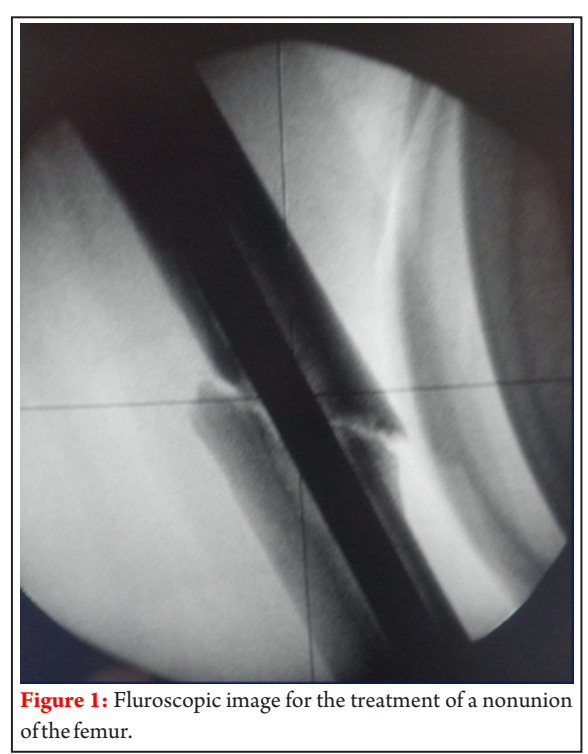

also be ruled out since other injuries and disorders may be associated.

Only a specialist medical doctor is trained and qualified to perform a complete clinical diagnosis, rule out associated injuries, request all the necessary complementary studies and, if necessary, opt for an invasive treatment of the lesion.

\section{When to Indicate Shockwaves?}

The ideal indication is considered to be when conventional conservative treatment has failed and as an alternative to surgery or other invasive procedures.

It is important to exhaust conventional conservative treatment before moving on to shock waves. Many of the musculoskeletal indications of shock waves have a good response with other methods that give faster results and are cheaper, therefore it is justified to treat only those cases that have not had an adequate result with them.

The basic recommendations for the indication of treatment are:

\begin{tabular}{|l|c|c|}
\hline \multicolumn{1}{|c|}{ Table 1: Indications according to diagnosis, technology and the degrees of recommendation according to scientific evidence [2,12]. } \\
\hline Calcifying tendinopaty of the shoulder & Technology & Grade of recommendation \\
\hline $\begin{array}{l}\text { Calcifying tendinopaty of the shoulder } \\
\text { Non calcific tendinopathy of the shoulder }\end{array}$ & Focused & A \\
\hline Lateral epicondilopathy of the elbow & Focused/Radial & I \\
\hline Greater trochanter pain syndrome & Focused/Radial & C \\
\hline Patellar tendinopathy & Focused/Radial & B \\
\hline Achilles tendinopathy & Focused/Radial & B \\
\hline Plantar fasciitis & Focused/Radial & B \\
\hline Bone non-union & Focused & A \\
\hline
\end{tabular}

\section{Patient over 18 years of age}

2. 2. Pain due to chronic tendinopathy diagnosed clinically by a medical specialist 3. Symptoms greater than 6 months

4. Previous medical treatment with Nonsteroidal anti-inflammatory drugs (NSAIDs), infiltrations and physiotherapy (more than two rehabilitation programs not continuous in a period not less than 3 months) without satisfactory clinical results 5. Patient scheduled for surgical treatment

6. Previous surgical treatment of tendinopathy without satisfactory clinical results.

\section{Contraindications}

Malignant tumor and fetus in the treatment area are absolute contraindications both for radial and focused waves. High energyfocused waves have been also contraindicated when lung tissue, epiphyseal plate, and brain or spine are underlying the treatment area [11]. The new indications in the brain and spinal cord are leading in both cases to go from being absolute to relative contraindications, but extreme care must be taken in application.

Large vessels and nerves should always be avoided when applying shockwaves [14].

\section{What Technology Should be Used?}

As we mentioned, there are shared indications and others specific to each method. To treat superficial soft tissue conditions, devices with or without focusing technology are useful; close attention must be paid to the depth of penetration of the shockwave source when treating deep tissue structures.

Comparison of the results of the use of focused and radial waves in pathologies such as lateral epicondylopathy, patellar 


\begin{tabular}{|c|c|c|c|c|c|}
\hline Parameters & Electrohydraulic & Electromagnetic & Parameters & Electrohydraulic & Electromagnetic \\
\hline Energy flux density & $0,2-0,32 \mathrm{~mJ} / \mathrm{mm}^{2}$ & $0,4-0,6 \mathrm{~mJ} / \mathrm{mm}^{2}$ & Energy flux density & $0,3-0,55 \mathrm{~mJ} / \mathrm{mm}^{2}$ & $0,4-0,6 \mathrm{~mJ} / \mathrm{mm}^{2}$ \\
\hline Frecuency & 1 to $5 \mathrm{~Hz}$ & 1 to $5 \mathrm{~Hz}$ & Frecuency & 1 to $5 \mathrm{~Hz}$ & 1 to $5 \mathrm{~Hz}$ \\
\hline Pulses & 2000 & 2000 to 3000 & Pulses & 2000 to 4000 & 3000 to 6000 \\
\hline Sesions & 1 to 3 & 2 to 4 & Sesions & 1 to 3 & 3 to 4 \\
\hline
\end{tabular}

tolerance.

Coupling gel should be used to ensure the best transmission of the waves to the target tissue and to allow a more comfortable application.

There are a large number of application heads available that influence the physical characteristics of the waves. The most frequently used in musculoskeletal pathology is $15 \mathrm{~mm}$.

Frequency is measured in Hertz. Radial devices usually have a maximum frequency between 15 and 20 Hertz. The most frequently used frequency ranges from 4 to 8 $\mathrm{Hz}$. The number of pulses varies between 2000 and 3000 per session. The number of sessions is in most cases 3 , with a weekly interval.

The post-application protocol includes sports rest to avoid overload, the use of analgesics avoiding NSAIDs and the excessive use of ice.

General Recommendations for the use of Focused Shock Waves

When applying focused waves, the type of generator to be used must be taken into account. Electrohydraulic generators typically have a wider focus and are less painful. Electromagnetic devices have a smaller focus and their application is usually more painful. The size of the focus of piezoelectric applicators that have multiple piezoelectric elements is usually the smallest of all.

For more specific indications of focused waves such as rotator cuff calcifications and bone pathology, patient feedback is not a reliable localization factor. Anatomical landmarks, ultrasonography [17], fluoroscopy (Fig. 1), and even computed tomography (CT) scans can be used [18].

The use of local anesthesia is also contraindicated, but general anesthetic sedation is useful when working with high energy levels, especially with electromagnetic generators.

The basic treatment protocols can be for the treatment of calcifications and non-unions can be seen in Tables 2 and 3 .

When treating bone healing delays and nonunions, the post-application protocol is immobilization or unloading according to the affected bone, similar to what would be done with the acute injury. The first radiographic examination is performed at 6 weeks and the final one at 12 weeks. If there is no conclusive evidence in the latter, a CT scan may be useful.

In rotator cuff calcifications we perform radiographic controls with the same time interval and we always incorporate a rehabilitation program.

\section{Overview}

Focused shockwaves and RPW had a fast development in the field of musculoskeletal disorders during the last decades. Although the procedures are safe and effective if used correctly, poor results and complications have been described due to misunderstandings and technical errors.

With an accurate diagnosis, adequate indications approved therapeutic protocols and proper application technique, F-ESWT, and RPW are very good non-invasive options for treating musculoskeletal disorders.

Declaration of patient consent: The authors certify that they have obtained all appropriate patient consent forms. In the form, the patient has given his consent for his images and other clinical information to be reported in the Journal. The patient understands that his name and initials will not be published, and due efforts will be made to conceal his identity, but anonymity cannot be guaranteed.

Conflicts of Interest: Nil. Source of Support: None.

\section{References}

1. Delius M, Brendel W. Historical roots of lithotripsy. J Lithotr Stone Dis 1990;2:161-3.

2. Moya D, Ramón S, Schaden W, Wang CJ, Guiloff L, Cheng JH. The role of extracorporeal shockwave treatment in musculoskeletal disorders. J Bone Joint Surg Am 2018;100:251-63.

3. Loske AM. Medical and Biomedical Applications of Shock Waves. Cham, Switzerland: Springer International; 2017. p. 19-42.
4. Novak P. Physics: F-SW and R-SW. Basic information on focused and radial shock wave physics. In: Lohrer $H$, Gerdesmeyer $L$, editors. Multidisciplinary Medical Applications. Heilbronn: Buchverlag; 2014. p. 2849.

5. Consenso de la Federación Ibero-Latinoamericana de Ondas de Choque e Ingeniería Tisular Sobre las Bases Físicas de las Ondas de Choque Focales y de las Ondas de Presión Radial. Available from: https://onlat.net/?page_id=2497 [Last accessed on 2021 June 09]. 
6. Eid J. ISMST Consensus Statement Terms and Definitions. https://www.shockwavetherapy.org/fileadmin/user upload/dokumente/P DFs/Formulare/Consensus_MBRadial_pressure_wave_2017_sS.pdf [Last accessed on 2021 June 09].

7. European Commission DG Health and Consumer. Medical Devices: Guidance document. Classification of medical devices. MEDDEV 2. 4/1. Available from: $h$ ttps://pdf4pro.com/download/medical-devices-guidancedocument-6fa97.html [Last accessed on 2021 June 09].

8. Digest Guidelines for Extracorporeal Shockwave Therapy. Available $f$ https://www.shockwavetherapy.org/fileadmin/user_upload/ISMST_Guidel ines.pdf [Last accessed on 2021 June 09].

9. Kibler WB. Value on the front end: Making the effective diagnosis for optimal treatment. Arthroscopy 2017;33:493-5.

10. Moya D, Ramón S, Guiloff L, Terán P, Eid J, Serrano E. Malos resultados y complicaciones en el uso de ondas de choque focales yondas de presión radial en patología musculoesquelética [Poor results and complications in the use of focused shockwaves and radial pressure waves in musculoskeletal pathology]. Rehabilitacion (Madr) 2021;2021:00031-1.

11. International Society for Medical Shockwave Treatment. Consensus Statement on ESWT Indications and Contraindications. Available from: https://www.shockwavetherapy.org/fileadmin/user upload/dokumente/P DFs/Formulare/ISMST consensus statement on indications and cont raindications_20161012_final.pdf [Last accessed on 2021 June 09].
12. Wright JG. Revised grades of recommendation for summaries or reviews of orthopaedic surgical studies. J Bone Joint Surg Am 2006;88:1161-2.

13. Ramon S, EspañolA, Yebra M, Morillas JM, Unzurrunzaga R, Freitag K, et al. Current evidences in shockwave treatment. SETOC (Spanish Society of Shockwave Treatment) recommendations. Rehabilitacion (Madr) 2021;55(4):291-300.

14. Wang CJ, Huang HY, Yang K, Wang FS, Wong M. Pathome-chanism of shock wave injuries on femoral artery, vein andnerve. An experimental study in dogs. Injury. 2002;33:439-46.

15. Buchbinder R, Ptasznik R, Gordon J, Buchanan J, Prabaharan V, Forbes $A$. Ultrasound-guided extracorporeal shock wave therapy for plantar fasciitis: A randomized controlled trial. JAMA. 2002;288:1364-72.

16. Njawaya MM, Moses B, Martens D, Orchard JJ, Driscoll T, Negrine J, et al. Ultrasound guidance does not improve the results of shock wave for plantar fasciitis or calcific achilles tendinopathy: A randomized control trial. Clin J Sport Med 2018;28:21-7.

17. Charrin JE, Noel ER. Shockwave therapy under ultrasonographic guidance in rotator cuff calcific tendinitis. Jt. Bone Spine 2001;68:241-4.

18. Sabeti-Aschraf M, Dorotka R, Goll A, Trieb K. Extracorporeal shock wave therapy in the treatment of calcific tendinitis of the rotator cuff. Am J Sports 2005;33:1365-8.

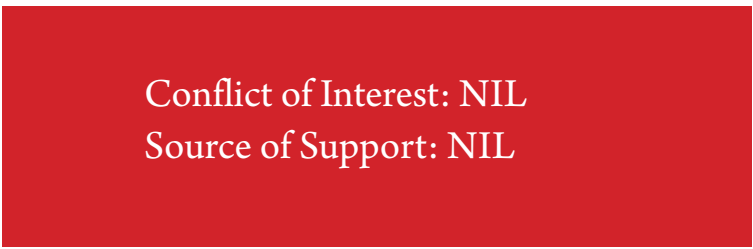

\section{How to Cite this Article}

Eid J, Moya D | Quality Standards and Techniques for the Application of Focused Shockwaves and Radial Pressure Waves in Musculoskeletal Disorders | Journal of Regenerative Science | December 2021; 1(1): 9-12. 